\title{
¿QUÉ DEMOCRACIA?
}

\section{POR}

ANTONI BENNÁSSAR MOYA

Profesor de Derecho Constitucional

Universitat de les Illes Balears 
SUMARIO:

L.INTRODUCCIÓN.-2. EL PODER DEL DEMOS.-3. EL IDEAL DE SOCIEDAD DEL TRABAJO Y LA DEMOCRACIA.4-. LA DEMOCRATIZACIÓN COMO MEDIO PARA UNA NUEVA DEMOCRACIA.-5. CONCLUSIONES 


\section{¿QUÉ DEMOCRACIA?}

POR

ANTONI BENNÁSSAR MOYA

Profesor de Derecho Constitucional

Universitat de les Illes Balears

\section{INTRODUCCIÓN}

A lo largo de la historia de la humanidad el término "democracia" ha tenido un significado ambivalente. En el siglo $X X$ la palabra democracia había alcanzado un grado de aceptación y popularidad inmensa. Sin embargo, bajo el término democracia, se habian enmascarado regímenes profundamente totalitarios. Debemos recordar en este sentido, las democracias populares instauradas en los regímenes satélites del socialismo real estalinista. En el caso español, no se puede olvidar, tampoco, que una dictadura se amparó, durante cerca de cuarenta años, bajo el término democracia orgánica. Se hace por ello necesario, tanto desde el Derecho como desde la filosofía política, el intento de clarificación terminológica de la palabra "democracia». Como afirma el profesor López Calera, a pesar de la larga historia de teorías sobre la democracia, no hay unanimidades sobre su definición, no hay conclusiones definitivas sobre qué es democracia'. Se produce incluso una especie de desilusión por la dificultad de ponerse de acuerdo sobre qué podemos entender por democracia.

En la configuración de la democracia moderna fueron decisivos dos acontecimientos históricos de suma importancia: las revoluciones políticas

${ }^{1}$ López Calera, N. M. : Filosofia del Derecho I, Editorial Comares, Granada, 1999, p. 171. 
burguesas y la revolución industrial. El primero de ellos supondría la aparición de la democracia liberal representativa sobre la base weberiana del homo oeconomicus; por otro lado, la revolución industrial conllevaría una cambio estructural de la sociedad y el trabajo sobre el pivote del homo laborans, y el nacimiento de un nuevo modelo de sociedad, la sociedad del trabajo. A partir de aquí, se irán estableciendo los estudios del fenómeno democrático vinculado a una discrepancia constante sobre qué debemos entender por democracia. Epítetos como directa, representativa, participativa, deliberativa, económica, industrial, real o formal, serán sólo algunos de los que se han utilizado para acompañar la palabra democracia en los siglos XIX y XX. Ante la dificultad que presenta el presente objeto de estudio, intentaré esbozar los elementos esenciales de las principales concepciones de la democracia para una correcta comprensión de la misma.

Este estudio se compondrá de tres partes: en primer lugar intentaré exponer brevemente los motivos de la histórica mala prensa de la democracia; seguidamente analizaré la aparición de la sociedad del trabajo, con los importantes cambios que conllevó en la teoría de la democracia, ligados a la figura del trabajador y a los planteamientos de democratización del puesto de trabajo; por último, pasaré al estudio del término democratización, vinculado a las tesis de democracia participativa.

\section{EL PODER DEL DEMOS}

El origen histórico de la palabra democracia se remonta al siglo $\mathrm{V}$ a.C. en la península griega. En el año 507 a. C., los atenienses adoptaron un sistema de gobierno popular que perduró durante casi dos siglos hasta que la ciudad fue sometida por Macedonia². Etimológicamente la palabra democracia proviene de las palabras griegas "demos" que significa pueblo, y «kratos" que supone gobierno ${ }^{3}$. Es de destacar que la utilización de la palabra "demos" no aludía en ocasiones al conjunto de ciudadanos, sino que se refería únicamente a la gente corriente o incluso a los pobres. Según Mossé4, el término "demos" designa en los textos oficiales atenienses al conjunto de los ciudadanos, mientras que en el lenguaje político cotidiano, era utilizado para designar a las "masas" populares (gente

2 DAHL, Robert: La democracia, una guía para los ciudadanos, Taurus, Madrid, 1999, p. 18.

3 Ibidem.

${ }^{4}$ Mossé, Claude: Historia de una democracia: Atenas, Akal Universitaria, Madrid, 1981, pp. 144 y ss. 
pobre), en oposición a los ricos o aristócratas. La palabra democracia parece que fue utilizada, en ocasiones, por sus críticos aristocráticos, como un tipo de adjetivo despectivo para designar su desprecio a la forma de gobierno que les había arrebatado el poder político, otorgándoselo a la gente común ${ }^{5}$. Esta idea de demos, de los pobres como mayoría numérica, recorrerá a lo largo de los siglos el pensamiento político. En efecto, esta concepción de la democracia, basada en la mencionada división social del cuerpo cívico en función de la riqueza, estará presente en la obra de Platón ${ }^{6}$ y Aristóteles ${ }^{7}$. El demos, para Aristóteles y otros filósofos clásicos, no estaba formado por el conjunto de la población, sino una parte: el estrato social de los pobres. Esta concepción de democracia como el gobierno de una parte de la población (los menos aventajados económicamente) en pro de sus propios intereses, contribuyó al desprecio del término ya que fuese relegado del lenguaje político durante unos dos mil cuatrocientos años. Como bien afirma Sartori ${ }^{8}$, durante más de dos mil años la palabra democracia había desaparecido de la lengua y había perdido cualquier connotación elogiosa. Durante ese largo período, en Occidente se habló de república; y decir res publica no era lo mismo que decir democracia. Semánticamente hablando, res publica expresa la idea de algo que pertenece a todo el mundo, o de los asuntos de todos (idea que se aparta sustancialmente de la noción clasista de un poder que pertenece al pueblo). La demokratia se presta a ser interpretada como el poder de una parte (que se opone a otra), mientras que la res publica no, y en tanto que aquel término se refiere a un sujeto definido (el pueblo), el último sugiere la idea del interés general y del bien común. Ni los constituyentes norteamericanos, ni los revolucionarios franceses (con la notable excepción de Robespierre ${ }^{9}$ )

5 DAHL, Robert: La democracia..., op. cit., p. 18.

6 "Nace pues la democracia, creo yo, cuando habiendo vencido los pobres, matan। a algunos de sus contrarios, a otros los destierran y a los demás les hacen participes delı gobierno y de los cargos, que, por lo regular, suelen cubrirse en este sistema mediante' sorteo.» (Platón: La República, 557 a).).

7 "... en efecto, la justicia democrática consiste en tener lo mismo numéricamente y no según el mérito; y siendo esto lo justo, el vulgo necesariamente es el dueño y en lo que está de acuerdo la mayoría, eso es la meta y eso es lo justo; ya que según ellosi cada ciudadano debe ser igual. Por consiguiente, en las democracias sucede que tienen। más autoridad los pobres que los ricos, pues son más, y la autoridad es aquello en lo que। está de acuerdo la mayoria.” (Aristóteles: Política, Libro VI, Capítulo II.). S HSI

${ }^{8}$ SARTORI, Giovanni: Teoría de la Democracia 2. Los problemas clásicos. Alianza, Editorial, Madrid, 1997, p. 357.

9 Robespierre empleó la palabra democracia, y ello al final de su discurso a la: Convención del 5 de febrero de 1794, asegurándose su mala reputación durante otro medio siglo (Sartori, op. cit., p. 359). 
tuvieron por ideal la democracia, sino que apostaban por la república. Esta opción por la república suponía un pronunciamiento por un ideal más moderado y prudente que el ideal democrático; un ideal compuesto del óptimo político que descarta la cosa de alguien (sea de uno solo o del demos) a favor de la cosa de nadie ${ }^{10}$.

Siglos después, con la revolución industrial y las revoluciones políticas burguesas, los grandes teóricos de la democracia liberal seguirán teniendo un rechazo absoluto a la democracia basada sufragio universal, apoyándose en la falta de formación $y$, por tanto, de recto juicio del pueblo asalariado en su hipotética participación política. Se reconocerá con el sufragio censitario o capacitarlo la opinión del pueblo, su doxa, pero únicamente de aquel pueblo formado e ilustrado, de aquél que tenga la formación académica necesaria para forjar una "verdadera opinión". Así, a título de ejemplo, Benjamín Constant en sus escritos políticos defenderá abiertamente que únicamente los que tengan recursos económicos para dedicarse a la actividad política y les hayan permitido previamente ilustrarse y formar una auténtica rectitud de juicio, debieran tener derechos de participación política: "Sólo la propiedad asegura el ocio necesario, sólo ella capacita al hombre para el ejercicio de los derechos políticos. "1". A partir de las revoluciones liberales, el demos ya no serán thetes y zeuguitas como en la democracia ateniense, sino que serán las masas obreras progresivamente concienciadas por la literatura socialista y la extensión de la educación. El rechazo a otorgar el poder político a las masas seguirá siendo un argumento recurrente por los aristoi (aristocracia) del liberalismo. A partir de este momento histórico, se convertirá en trascendental el papel del obrero y de su organización colectiva en sindicatos y partidos de clase, para el estudio de la democracia. La moderna teoría de la democracia no podrá entenderse al margen del trabajador asalariado y del ambiente en el que está inserto, la sociedad del trabajo.

\section{EL IDEAL DE LA SOCIEDAD DELTRABAJOY LA DEMOCRACIA}

El 26 de noviembre de 1984, Jürgen Habermas pronunciaba una conferencia en el Congreso de los Diputados español ${ }^{12}$. En ella defendía que la sociedad occidental estaba viviendo el.fin de una determinada utopía: la

${ }^{10}$ SARTORI, Giovanni: Teoria de la Democracia ..., op. cit. , p. 360.

11 Constant, Benjamín: Principios de política. Editorial Aguilar, Madrid, 1970, p. 57.

12 Conferencia bajo el título «Sobre la pérdida de confianza en si misma de la cultura occidental" publicada en la Revista de las Cortes Generales, no 3, tercer cuatrimestre, 1984. 
utopía de la sociedad del trabajo. Durante años, el comunismo soviético, el corporativismo autoritario fascista y el reformismo del Estado social se sustentaban sobre la sociedad del trabajo y el papel determinante en ella del trabajador. Esta visión trascendental del trabajo asalariado en la conformación de la política provenía de los cambios drásticos que se produjeron con la revolución industrial y el nacimiento del capitalismo. Para Ulrich Beck ${ }^{13}$, sucedió un cambio importantísimo en la concepción del hombre, de la política y del trabajo. En la Grecia y Roma clásicas, la libertad era un término incompatible con el trabajo; quien tenía que trabajar no sólo no era libre, sino que tampoco era miembro de la sociedad. La polis suponía la asunción de la necesidad de la sociedad esclavista extrahumana y del sometimiento de la mujer. Si en aquel tiempo el trabajo excluía al individuo de la sociedad, en las sociedades modernas se ha convertido en un valor nuclear $e$ integrador, prácticamente sin ninguna alternativa. En la Edad Moderna, nace la idea de la democracia como democracia del trabajo, en el sentido de que la democracia viva presupone (en Europa y EE.UU. principalmente) el participar activamente en el trabajo remunerado. El ciudadano no se concibe si no es como ciudadano trabajador. Desde la aparición de la industria y el fin del Antiguo Régimen, el trabajo es una parte esencial de la vida de las personas. Esto supone que, lejos de entenderse como una pesada carga o una "maldición divina» como en tiempos pasados, el trabajo se transforma en un elemento esencial de la dignidad personal. El trabajo se convierte en un derecho conducente al estatus de ciudadano, siendo también un deber inherente a este estatus ${ }^{14}$. Si Max Weber ${ }^{15}$ configuró la evolución homo politicus, homo credens, homo oeconomicus, ahora podríamos hablar de una cuarta categoria: el homo faber u homo laborans.

En esta configuración del hombre como trabajador, como productor, tendrá una especial incidencia la obra de Marx. Apunta García Marza ${ }^{16}$, que Marx añadirá un aspecto esencial en el análisis de la antropología humana. En efecto, para el autor de Das Kapital, si lo característico del hombre es el trabajo, habrá que ver en sus condiciones por qué no constituye una fuente de liberación sino de esclavitud. En tanto que no se produzca una evolución del modo de producción burgués o capitalista, a un nuevo orden económico y político totalmente nuevo, el comunismo, estaremos en una etapa

${ }^{13}$ BECK, Ulrich: Un nuevo munto feliz,: La precariedad del trabajo en la era de la globalización, Paidós, Barcelona, 2000, pp. 19 y ss.

14 SÁnCHEZ-Mora Molina, M. ${ }^{a}$ I.: "Bienestar y Malestar social: De la sociedad del trabajo a la sociedad postlaboral", en Aranzadi Social, n. ${ }^{\circ} 22$, Marzo 2002.

15 Weber, Max: Economía y Sociedad: Un esbozo de sociología comprensiva, Fondo de Cultura Económica de Mexico, México, 1944, p. 1035.

${ }^{16}$ García Marzá, V. Domingo: Teoría de la Democracia, op. cit.,p. 95. 
de transición. Mientras tanto, hasta llegar a este momento, debe pensarse una nueva reestructuración de la relación sociedad civil-Estado, en la que el trabajador y el trabajo asalariado tendrán que tener un papel relevante.

De este modo, del pensamiento de Marx podemos deducir un aspecto esencial que recorre su obra. Marx tendrá, a juicio de Popper, una visión de la libertad fuertemente influenciada por la obra de Hegel. Pensará que la libertad es el fin del desarrollo histórico, identificando el reino de la libertad con el de la vida espiritual del hombre. Sin embargo, incluirá un aspecto novedoso en el su configuración del concepto de libertad; Marx reconocerá que no somos seres puramente espirituales, que no somos plenamente libres ni capaces de alcanzar alguna vez la libertad completa, imposibilitados como estamos y estaremos siempre de emanciparnos de las necesidades de nuestro metabolismo y, de este modo, de la obligación de trabajar para producir. Señala Popper ${ }^{17}$ que partiendo de esta determinada visión de la libertad que tiene Marx ${ }^{18}$, todo lo más que podemos lograr los seres humanos es mejorar las agobiantes e indignas condiciones de trabajo, ponerlas más acordes con los ideales del hombre y reducir la labor a una medida tal que todos nosotros seamos libres durante cierta parte de nuestras vidas. Es ésta, a juicio de Popper, la idea central de la "concepción de la vida" de Marx; central, asimismo, en la medida en que parece ser la que más influencia ha tenido de todas sus teorías. La obra marxiana supone un

17 POPPER, K. R.: La sociedad abierta y sus enemigos, Paidos, Barcelona, 1981, p. 288.

18 Popper se refiera en concreto a un pasaje del Libro III del Capital en que Marx expresa lo siguiente: “De hecho, el reino de la libertad sólo comienza alli donde cesa el trabajo determinado por la necesidad y la adecuación a finalidades exteriores; con arreglo a la naturaleza de las cosas, por consiguiente, está más allá de la esfera de la producción material propiamente dicha " (MARX, Karl: El capital. Libro III, Editorial Siglo XXI, Madrid, 1981, página 1044) Sin embargo, hablar de la libertad en Marx siempre es complicado. Marx en su manuscrito La cuestión Judia , vierte una dura crítica a la reducción burguesa de la libertad a la propiedad privada (MARX, Karl: Manuscritos de París, Crítica, Barcelona, 1978, página 195). Este reduccionismo va vinculado a un retorno del individualismo frente a la comunidad "Pero el derecho humano de la libertad no se basa en la vinculación entre los hombres sino al contrario en su aislamiento, el derecho de este aislamiento, el derecho del individuo restringido, circunscrito a sí mismo« (lbideni). La misma intención se deduce de otros textos marxianos, como por ejemplo la introducción a los Grundisse, al criticar las "robinsonadas dieciochescas' (MARX, Karl: Elementos fundamentales para la crítica de la economía política. Siglo XXI, México, 1972, volumen I, pp. 3 y ss.). La libertad para Marx será una libertad que se alejará de los presupuestos del liberalismo clásico que parten de un individuo átomo, el punto de inicio sobre el que construir el edificio de la libertad marxiana será el individuo social y en especial el trabajador, el homo faber en definitiva. A partir de ello, se deberá tener presente que el hombre sólo se le podrá considerar verdaderamente libre si es libre en su trabajo; si es asas libre como trabajador y no tan sólo como ciudadano. 
cambio importantísimo dentro del pensamiento social y político: el papel del trabajador, del productor y del mercado de trabajo se convertirán a partir de la crítica marxiana en el epicentro del estudio de las ciencias sociales. El análisis político partirá, de manera directa o indirecta, de lo que podríamos denominar sociedad del trabajo. Intentando sintetizar al máximo este concepto, se puede decir que, partiendo de la idea de que la mayor parte de la población debe trabajar para obtener sus medios de subsistencia, y que, por tanto, las relaciones laborales están de facto en la base del sistema económico y político de cualquier sociedad, cualquier planteamiento político de cambio social deberá pasar necesariamente por un cambio o alteración de las relaciones laborales ¿cómo afectará esta sociedad del trabajo a la teoría del Estado y la democracia?

El capitalismo se había construido sobre la Administración, la codificación, la racionalización y la utilización coactiva del Derecho. De este modo, el Estado nacido de las Revoluciones políticas burguesas será lo que se denominará Estado de Derecho. En este aspecto, tomo el argumento esgrimido por Max Weber, al afirmar que la empresa capitalista moderna descansará ante todo en el "cálculo". De este modo, necesitará de una Justicia y una Administración cuyo funcionamiento pueda calcularse racionalmente, por lo menos en principio, por normas fijas generales con tanta exactitud como puede calcularse el rendimiento probable de una máquina ${ }^{19}$. No puede contentarse el capitalismo con la «justicia del Cadí». Las formas de empresa moderna, con su capital fijo y su cálculo exacto, son demasiado sensibles frente a las irracionalidades del Derecho y de la Administración. La empresa capitalista moderna descansa internamente ante todo en el cálculo. De esta manera, el sistema capitalista sólo se podrá originar en dos modelos de sistema jurídico: el anglosajón sustentado en la idea del stare decisis, ${ }^{20}$ y el continental fundamentado en el positivismo jurídico, el Estado burocrático y el juez profesional ${ }^{21}$. El Estado de Derecho, el Rechtsstaat, será el paradigma del homo oeconomicus, pero, ¿dónde queda en este Estado de Derecho el homo laborans surgido de los cambios emanados de la revolución industrial, y que según Marx tiene que convertirse en el protagonista de la historia?

${ }^{19}$ WeBER, Max: Economía y Sociedad... , op. cit. , p. 1.062.

${ }^{20}$ Sobre el principio stare decisis, puede verse el trabajo de Luis López Guerra titulado: "El Tribunal Constitucional y el principio stare decisis», en El Tribunal Constitucional, Dirección General de lo Contencioso del Estado, Instituto de Estudios Fiscales, Madrid, 1981, vol. II, pp. 1.433-1455.

21 WeBER, Max: Economía y Sociedad... , op. cit. , p. 1.062. 
Si el homo oeconomicus se apoyaba sobre el Estado de Derecho, el homo laborans lo hará sobre el Estado social22. La idea de Estado social supondrá una primera superación del modelo clásico de democracia representativa. La propia configuración de un Estado interventor supondrá la inclusión de una serie de características que desbordan la idea liberal de Estado. Se produce un aumento importante del aparato estatal y por tanto también del burocrático; aparece la configuración e inclusión constitucional de los derechos sociales y económicos, superando la idea de los derechos políticos vistos desde una óptica estrictamente negativa y por tanto abstencionista del poder estatal. Todo ello va unido a la crítica constante que, prácticamente durante un siglo, había dirigido el movimiento socialista contra el sistema político vigente. Este conjunto de factores llevarán al planteamiento de nuevas formas de articulación del modelo democrático. Esta nueva sociedad del trabajo, con el papel central que desempeña el trabajador en la vida social y política, supondrá la consolidación de un nuevo proyecto democrático que irá ligado irremediablemente a la existencia de un innovador modelo de Estado y de relaciones sociales. Ante la experiencia de la II Guerra Mundial, se consolidará en los países con democracias representativas y economías de mercado, aquello que se vino en denominar Estado de bienestar ${ }^{23}$. El modelo de

22 H. Heller, acuña en 1929 la expresión «Estado social de Derecho", idea que trata de responder a la crisis histórica del modelo europeo de sociedad del primer tercio del siglo XX. Se trata de un intento de superación de la diferencia entre la formalización jurídica de los derechos y su ejercicio efectivo por parte de todos, lo cual exigía una doble vía de realización: de un lado, cambiar el estatuto del ciudadano, que no debe ser ya sólo una persona integrada en un país politica y jurídicamente sino también económica, social y culturalmente; de otro, cambiar el estatuto jurídico-político del poder público, que, de ser meramente vigilante y represor, pasa a ser ordenador, conformador de la sociedad y promotor de un nuevo ciudadano partícipe (TORRES DEL MORAL, A. : Estado de Derecho y democracia de partidos. Servicio de Publicaciones de la Facultad de Derecho de la Universidad Complutense de Madrid, Madrid, 1991, p.73.).

${ }^{23}$ Podremos distinguir, como hace Requejo Coll (ReOUeJo ColL, Ferran: Las democracias: Democracia antigua, democracia liberal y Estado de bienestar, Ariel, Barcelona, 1994, pp. 124 y ss.) los conceptos Estado social y Estado de Bienestar. El concepto Estado socia/vendría a designar una organización política estatal desarrollada en los países capitalistas industrializados durante los últimos cien años, y asociada a una serie de medidas intervencionistas por parte de los poderes públicos que rompen con la noción liberal de la independencia del mercado como principal agente regulador de las interrelaciones económicas de una sociedad. Por el contrario, el concepto Estado de Bienestar tendría un sentido temporal más restringido, siendo circunscrito a las estructuras políticas vigentes en los sistemas democráticos de la tradición liberal a partir, sobre todo, de la Segunda Guerra Mundial. Este mismo criterio distintivo es afirmado por Luhmann (LUHMANN, N. : Teoria política en el Estado de Bienestar, Alianza, Madrid, 1993, p.31), considerando que el concepto bienestar significa y exige algo más que la mera asistencia social como reacción a los problemas derivados de la industrialización. 
Estado asistencial, con un papel más que destacado en la economía y en la acción social ayudaría a consolidar una democracia que partiendo de lo político se pretendía abrir a otros ámbitos. El proceso que habia culminado con el sufragio universal masculino se extendió a la mujer, incorporándose las: premisas democráticas a otros ámbitos donde antes ni tan siquiera se habían: planteado.

Dentro de esta fase de extensión democrática, se produjeron una serie de cambios organizativos e ideológicos en la configuración de la actividad empresarial, que dieron lugar a una serie de fenómenos diversos de: democratización de la esfera laboral. La vía consejista ${ }^{24}$, realizada en la Revolución Soviética, había supuesto la articulación de un modelo político: sobre el pilar del puesto de trabajo; a ello se le unió el hecho de que en la posguerra europea asumieron un papel importantísimo las organizaciones: políticas y sindicales de corte socialista y comunista ${ }^{25}$, con una fuerte: influencia del componente marxista en su ideario. Ante el panorama: expuesto, se fueron articulando, en la mayoría de países europeos occidentales con economías capitalistas, mecanismos de participación de los trabajadores asalariados en las empresas societarias; mecanismos que a pesar, de su diversidad de formas, fueron englobados en un concepto genérico de democracia industrial ${ }^{26}$. Por primera vez, en sociedades políticas constituidas sobre principios de democracia representativa, economía de mercado $y$.

24 A pesar de que sea un concepto que se desarrollará más adelante, podemos adelantar que por vía consejista de organización política se puede definir a todo un conjunto de planteamientos basados en la substitución de una estructura política parlamentaria-representativa, por una nueva sustentada sobre la base de consejos asamblearios estructurados jerárquicamente desde una base soberana.

25 Fue decisivo en la consolidación del Estado social el papel de los partidos de izquierda. Tras la II Guerra Mundial, las primeras elecciones francesas dieron la mayoría al Partido Socialista (SFIO) junto al Partido Comunista Francés (PCI); en Italia, los liberales quedaron relegados frente a la Democracia Cristiana que se habia decantado muy a la izquierda en cuestiones sociales tras la derrota del fascismo, unido al importantísimo peso electoral del socialismo italiano y del movimiento comunista. En Inglaterra, las primeras elecciones tras 1945 dieron una victoria acaparadora al laborismo. La gran excepción europea fue Alemania con la victoria del demócrata cristiano Adenauer, que impidió a la socialdemocracia gobernar hasta 1969 con la victoria de Willy Brandt. Para entender la influencia del socialismo democrático en la configuración del Estado social es destacable la obra de Wolfgang Abendroth "El Estado de Derecho democrático y social como proyec: to políticon, en AA. W., El Estado Social, CEC, Madrid, I 1986, en especial p. 14 y ss.

26 Shumpeter (Shumpeter, J. A.: Capitalismo, Socialismo y democracia, Orbis; Barcelona, 1983, pp. 380-381) dará dos grandes conceptos del término «democracia industrial «. Primero, el dominio de los sindicatos sobre las relaciones industriales; segundo, la democratización del sistema monárquico de gestión de la fábrica, mediante la representación de los obreros en las juntas directivas o mediante otras fórmulas ideadas 
substrato ideológico liberal, se había consolidado una nueva forma de democracia. Esta nueva forma de democracia no era ya tan sólo un planteamiento utópico o hipotético, sino que adquirió rango de ley, penetrando profundamente en la mentalidad juridica y social, consolidándose paulatinamente desde un punto de vista legislativo. Sin embargo, esta nueva democracia industrial se encontraba con una seria dificultad. Si la democracia política tiene un prius, un requisito ineludible, como es la igualdad entre el cuerpo político, entre los cives (igualdad que llegará a su culminación con la premisa del sufragio universal: un hombre un voto); los mecanismos de democracia industrial vienen caracterizados precisamente por un rasgo definitorio como es la desigualdad de las partes. Las relaciones laborales están definidas, incluso en los regímenes políticos fuertemente democráticos, por los principios de jerarquía, disciplina y subordinación ${ }^{27}$. El deber de obediencia será una característica manifestación de la dependencia del trabajador respecto del empresario $y$, al mismo tiempo una clara prueba de la tan alegada desigualdad socioeconómica entre trabajadores y empresarios es también $y$ ante todo una desigualdad jurídica: el empresario ordena y el trabajador obedece; sus relaciones son jerárquicas y no paritarias o de igualdad ${ }^{28}$. El trabajador parte de una posición jurídica y táctica de franca desigualdad con respecto a los dirigentes y/o titulares dominica-

para asegurar a los obreros una influencia en la introducción de mejoras técnicas en la política de la empresa en general y, por supuesto, en la disciplina de la fábrica en particular, incluyendo los métodos de admisión y despidos. El primero de ellos, desde mi punto de vista, iría ligado al modelo revolucionario; mientras que el segundo, estaria incardinado en premisas reformistas. En todo caso, los mecanismos de participación industrial experimentados en sociedades capitalistas pueden resumirse en cinco: las cooperativas de productores o trabajadores, la negociación colectiva, la representación a través de comité de empresa o sindicatos, las formas de participación a nivel de centro de trabajo y los programas de participación obrera en los beneficios y empleado-accionista (Poole, M.: Hacia una nueva democracia industrial, MTSS, Madrid, 1995, p. 222).

27 Para citar a título de ejemplo nuestro Derecho positivo, el Estatuto de los Trabajadores (Real Decreto Legislativo 1/1995, de 24 de marzo, BOE de 28 de marzo) establece en su art. 5 .c) como deber básico del trabajador, el cumplir las órdenes e instrucciones del empresario en el ejercicio regular de sus facultades directivas. Este artículo se completa con el 20 del propio E.T. (dirección y control de la actividad laboral) y con el 54.2.b) que considera la indisciplina o desobediencia en el trabajo como causa de despido disciplinario. La configuración actual del E.T. supone en todo caso un avance notable con respecto al antiguo art. 69 de la Ley de Contrato de Trabajo, siendo también este deber de disciplina y obediencia matizado por la jurisprudencia del Tribunal Constitucional (STC 120/1983 de 15 de diciembre y reafirmada por la STC 6/1995 de 10 de enero, vinculando el deber de obediencia al respeto del haz de derechos fundamentales reconocidos en la Constitución) y del Tribunal Supremo (entre otras STS de 21/9/87 y STS de 9/10/89).

28 Montoya Melgar, A.: Derecho del Trabajo, Tecnos, Madrid, 1997, p. 327. 
les de la empresa. Esta desigualdad inicial es una de las bases sobre las que se iniciaron las reflexiones sobre una nueva forma de democracia que partiera del puesto de trabajo. Sidney y Beatrice Webb escribieron en el año 1897 su famosa obra Industrial Democracy, en ella plasmarían una idea que recorrerá todos los planteamientos pasados y presentes de democratización laboral: "En el Estado democrático cada individuo es a la vez amo y servidor. En el trabajo que lleva a cabo para la sociedad a cambio de sus medios de subsistencia es, y no puede dejar de ser, un servidor, sometido a las instrucciones y directrices de aquellos cuyos deseos contribuye a satisfacer. ${ }^{29}$. Asi se reflejaba una de las grandes contradicciones de la burguesía liberal, que habia luchado contra la esclavitud del feudalismo en el Antiguo Régimen. La nueva libertad política emanada de las revoluciones políticas burguesas fue rápidamente difuminada con los efectos de la revolución industrial. Con la industrialización se originó la dictadura del mercado y la esclavitud del puesto de trabajo, que condenaba a la miseria y a la subordinación a amplias capas de la población. El liberalismo había convertido a los súbditos en ciudadanos formalmente libres, pero que en el puesto de trabajo seguían siendo considerados como esclavos. De este modo, los primeros demócratas industriales minimizaban los avances de la civilización, arguyendo que, incluso en las sociedades libres, el obrero era un «esclavo asalariado ${ }^{30}$. Partiendo de esta desigualdad jurídica y real existente en las relaciones de trabajo se presentaba un problema ¿Cómo conseguir, por parte de los trabajadores, un poder influyente en la dirección empresarial, tanto en asuntos relativos a las relaciones laborales, como a aspectos genéricos de la actividad industrial? La respuesta está, entre otros factores, en la organización colectiva de los trabajadores. Si la democracia representativa liberal se había construido sobre las bases del individuo aislado (atomismo) y las premisas contractualistas, el poder de los trabajadores en la segunda mitad del siglo XX irá ligado a la colectividad, a las masas, a lo que podríamos denominar conciencia de intereses comunes $y$ al papel decisivo de los sindicatos en la vida social y política ${ }^{31}$. Fue la integración del trabajador en organizaciones colectivas, los sindicatos, lo que le permitió superar la franca desigualdad inicial de la que partía. Estos sindicatos, con un fuerte componente

${ }^{29}$ WebB, Sidney and Beatrice: Industrial Democracy, Longmans, Oreen, and Co, New York and Bombay, 1897,p. 844.

${ }^{30}$ CLEGG, H. A.: Una nueva democracia industrial. Hispano Europea, Barcelona, 1966, p. 33.

${ }^{31}$ Téngase en cuenta que durante mucho tiempo, al Derecho Laboral se le denominó Derecho social, ya que se refería a lo que fue bautizado como "cuestión social». El Derecho delTrabajo fue una respuesta al individualismo juridico, proporcionando, desde la regulación normativa de la relación laboral, las bases para el goce efectivo de las libertades formales. 
ideológico y vinculación política a determinados partidos políticos, fueron los grandes artífices de los mecanismos de participación obrera en el seno del puesto de trabajo. No obstante, estos instrumentos participativos provocaron unas consecuencias imprevistas. Curiosamente, el establecimiento de mecanismos de participación de los trabajadores en la empresa, que había tenido unos fundamentos ideológicos vinculados al marxismo, tuvo un papel determinante en la consolidación de la democracia liberal representativa. De este modo, en un principio, los propios trabajadores se mostraron reacios (y con razón) a compartir las responsabilidades de dirección ${ }^{32}$. Por tradición, los sindicatos habían desconfiado de todos los proyectos de participación y colaboración con los empresarios, temiendo dejarse "domesticarn $^{33}$. Habían preferido mantenerse al margen y guardar intacta su capacidad de oposición y ejercer su derecho de huelga. Sin embargo, la extensión paulatina de mecanismos de participación obrera, supuso, junto a otros factores como el progresivo bienestar económico alcanzado por los trabajadores en el seno del Estado de bienestar, desactivar el espíritu revolucionario y la consolidación del sistema capitalista evolucionado. Así, de este modo, la ruptura del sacrosanto derecho de propiedad industrial con su correlato direccional, supuso, paradójicamente, la mayor aportación a la consolidación del capitalismo. El establecimiento de mecanismos de participación en el puesto de trabajo no llevó al socialismo de los soviets, sino que los descartó definitivamente.

32 G. SAN MigueL, L. : “Participación en el poder y control de las élites como problemas de la democracia moderna", en Revista de Estudios Políticos, n. ${ }^{\circ} 143$, Madrid, 1965, p. 113.

33 En este sentido CLEGG (CLEGG, H. A.: Una nueva..., op. cit., p. 35) defenderá la independencia del sindicalismo, tanto respecto de la empresa como del Estado, ya que de no serlo los sindicatos no podrian actuar como una verdadera oposición; si las fuerzas sindicales llegaran a formar parte de la dirección empresarial o si sus actividades quedaran sujetas a decisiones gubernamentales perderían su fuerza principal: su independencia. Esta polémica tuvo especial incidencia dentro del Partido Comunista Italiano fruto del movimiento consejista de 1969. Este movimiento derivaba de unas bases ideológicas fundamentadas en la revolución consejista de fábricas producida en Turín en el año 1920 bajo la dirección de Gramsci. Dicha polémica enfrascó principalmente a Lucio Magri frente a Pietro Ingrao (puede verse un síntesis de la polémica en AA. VV., Vía Parlamentaria o Vía consejista. Anagrama , Barcelona 1977), y se centraba en el papel que debían tener los consejos, sindicatos y el partido en la construcción del socialismo. 


\section{LA DEMOCRATIZACIÓN COMO MEDIO PARA UNA NUEVA DEMOCRACIA}

Pasquino ${ }^{34}$ afirma que en los escritos recientes de los grandes autores sobre la democracia (Dhal, Lindblom, Bobbio, Huntington...), aparece una idea: una especie de Gleichstaltung democrática. Para que la democracia se afirme, se consolide, se extienda, sería indispensable que se convirtieran en democráticas las fuerzas armadas, la burocracia, las escuelas, las asociaciones representativas de intereses comenzando por las grandes empresas, sindicatos y, por qué no, incluso las iglesias.

¿Supondría ello un cambio en la concepción que ahora nosotros tenemos de la democracia? ¿Cuál sería esa nueva democracia? ¿Conllevaría ese proceso democratizador algún tipo modificación, supresión o extensión de la democracia política representativa clásica?

En primer lugar, debemos intentar delimitar qué entendemos por democracia política y a partir de aquí, diferenciarla de la aplicación de reglas de decisión democráticas (normalmente por analogia con los mecanismos de democracia representativa clásicos) a ámbitos que históricamente han estado sometidos a decisiones autocráticas. De este modo, Sartori ${ }^{35}$ diferencia la democracia politica de las otras democracias. La democracia sin calificativos será la democracia política. Las demás democracias serán subordinadas y condicionadas a la primera. Pero, ¿cuáles son esas otras democracias? ¿qué relaciones tienen con la democracia política? Esta idea de democratización apuntada por Pasquino y Sartori irá, desde mi punto de vista, estrechamente ligada al concepto de democracia participativa. Para abordar el estudio del término democracia participativa, la primera distinción que debemos hacer es diferenciar lo que podíamos denominar democracia como hecho político, que sería objeto de estudio por parte del constitucionalismo y la ciencia política ${ }^{36}$, de la democracia como ideal, como meta o desiderátum, que estaría en la órbita de la filosofía jurídico-política. Al pasar a analizar el fenómeno democrático desde premisas de deber ser

34 Pasouino, Gianfranco: La democracia exigente, Alianza Editorial, Madrid, 2000, p. 22.

35 SARTORI, Giovanni: Elementos de Teoría Política, Alianza Editorial, Madrid, 1999, p. 34.

36 Un ejemplo típico de un estudio empírico contemporáneo de este tipo sobre la democracia, sería la obra Modelos de democracia: Formas de Gobierno y resultados en treinta y seis países de Arend Lijphart (Alianza, Barcelona, 2000), sin olvidar la ingente labor que hizo en su día García Pelayo con su magistral obra Derecho constitucional comparado (Alianza, Madrid, 1999). Sin embargo, al intentar plantear desde la órbita filosófica cambios en el modelo democrático, se debe partir de una moral crítica superadora de los propios textos legales y constitucionales de cada Estado. 
deberemos replantearnos cuál el modelo de democracia por el que debemos optar. A partir de estas bases, Carlos Santiago Niño distinguió dos grandes modelos de estudio en función de la incorporación de criterios morales en la justificación y explicación de la democracia ${ }^{37}$ :

a) El primer gran grupo de teorías reservaria al funcionamiento de la democracia un ámbito dentro del cual los asuntos morales no entrarían en juego. La democracia generaría una dinámica de acción colectiva que produciría resultados moralmente aceptables pero no debería tratar de modificar las preferencia y los intereses de la gente en una dirección moralmente virtuosa. Estos argumentos, partiendo de un escepticismo ético o relativista, tienden a dudar de la existencia de razones objetivas para descalificar las preferencias de las personas como inmorales. Si la aceptación de razones morales objetivas conduce a proyectos políticos autoritarios, la gran virtud del proceso democrático estaría en que éste opera de forma tal que nadie pueda descalificar las preferencias de ningún otro individuo como inmorales, $y$ en que el sistema busca acomodar las preferencias de todos sin juzgar acerca de su contenido moral.

b) La segunda gran familia de teorías para justificar la democracia adoptaria un enfoque exactamente opuesto, insertando el proceso democrático dentro del dominio de la moral. De acuerdo con esta concepción, la virtud de la democracia radica precisamente en la incorporación de mecanismos que transforman las preferencias autointeresadas originarias de las personas en otras más altruistas e imparciales. Estas posturas huirian del relativismo o escepticismo metaético, afirmando que existe la posibilidad de dar razones objetivas respecto de la moralidad de ciertos resultados y que el proceso democrático mismo ayuda a determinar el resultado moralmente correcto.

La primera de estas corrientes sobre la teoria de la democracia, estaría vinculada a los conceptos "democracia liberal", "democracia constitucional" o "democracia representativa». La segunda de estas familias, iría ligada a los modelos de "democracia populista", "democracia social" o "democracia participativa".

Analizados los fundamentos éticos de estas dos grandes escuelas sobre las que se entronca la moderna teoría de la democracia, pasemos a

37 Santiago Niño, C.: La Consunción de la democracia deliberativa, Gedisa, Barcelona, 1997, pp. 101 y ss. 
analizar de manera más detallada los presupuestos de democracia participativa, que han sido el mayor aporte ideológico que ha servido de sustento a las propuestas democratizadoras de la democracia.

Adela Cortina propondrá dos grandes modelos que se han planteado para la consecución de una democracia participativa ${ }^{38}$ :

a) El modelo de democratización de los subsistemas sociales ${ }^{39}$, que distingue en el conjunto de la sociedad entre lo que tradicionalmente se considera sistema político y el resto de los subsistemas, y propone mantener en lo esencial el sistema político de democracia representativa, con algunas correcciones poco profundas (reformas en las elecciones, introducción de consultas populares, participación del pueblo en planificaciones a largo plazo, pasos para una des-oligarquización de los partidos), y como segunda gran base, democratizar las instituciones tradicionalmente no políticas, como empresas, escuelas, universidades, fuerzas armadas, etc. Al hablar aquí de democracia radical o participativa, tal predicado no tiene que entenderse como opuesto al de democracia representativa en el sentido de exigir, por ejemplo, una democracia asamblearia o directa ${ }^{40}$. Para García Marzá, esta idea de democracia radical o participativa sería resultado de una necesaria transformación, dentro de los principios constitucionales reconocidos, de las instituciones políticas actuales, apoyadas en su mayor parte en una despolitización y burocratización, en una, en definitiva, pérdida de valores morales de la esfera pública. Mientras los partidos políticos, los canales de representación, los expertos de la administración pública mantengan apartadas sus

38 Cortina, A.: Ética aplicada y democracia radical, Tecnos, Madrid, 1993 p. 93.

${ }^{39}$ En cuanto a los susbsitemas, Habermas (HABERmAS, J.: Facticidad $y$ validez, Trotta, 1998, pp. 413 y ss) definirá la teoría de los sistemas como aquélla que considera la sociedad como una red de subsistemas autónomos que se encapsulan unos frente a otros adoptando cada uno su propia semántica. Así se distinguiría entre el sistema político, especializado en la producción de decisiones colectivamente vinculantes, y el resto de sistemas funcionales (entre los que se incluiría, a título de ejemplo, el jurídico). LUHMAN (LUHMAN, N.: Teoría política en el Estado de Bienestar, Alianza, Madrid, 1981, pp. 41-42) afirmará que esta distinción entre sistemas partirá de la separación producida a finales del siglo XIX entre Estado y sociedad. De este modo, la sociedad es un sistema social omnicomprensivo que ordena todas las comunicaciones posibles entre los hombres. El sistema político sería uno de sus subsistemas, respecto del cual se han ido diferenciando otros susbsistemas, en particular sistemas como la religión, ciencia, economía, educación, etc. Esta distinción entre sistemas no impedirá fuertes dependencias recíprocas entre ellos.

40 García Marzá, V. D.: Ética de la Justicia, Tecnos, Madrid, 1992, p. 188. 
decisiones de la participación pública, se mantendrá alejada una determinada organización política del calificativo de «justa». Deberá ser la participación, como el socialismo democrático reclama, el punto de partida para la extensión y profundización de la democracia ${ }^{41}$.

b) El modelo de descentralización política, según el cual la democracia representativa se eliminaría y se crearían dos instancias que toman decisiones que obligan a los ciudadanos: las unidades sociales de base, de las que arrancan las decisiones, y una instancia central, que ha de mantener el orden y coordinar las tareas. Este modelo se ligaría a la obra de Rousseau, Jefferson, y a socialistas como Owen, Fourier, Marx, Lenin y Colé entre otros.

En este punto, vincularía las dos formulaciones de democracia participativa a las críticas socialistas que se formularon contra la democracia liberal burguesa desde grandes planteamientos ideológicos: el socialismo revolucionario marxista y la democracia social de corte social-reformista. Desde finales del siglo XIX, el socialismo se había venido planteando dos grandes modelos de transformación revolucionaria de la estructura política y productiva de la sociedad. Sin embargo, la parcela donde existió mayor desacuerdo entre los socialistas, era en el punto de la transición al socialismo. Desde posturas igualmente críticas con la democracia liberal, se configurarán dos grandes modelos de teoría crítica de la democracia. Estas teorías fueron reflejo de las diferentes maneras históricas de entender el socialismo y del determinante proceso de transición de un sistema económico $y$ social capitalista a uno socialista. De este modo, la huelga general, la insurrección de las masas, la vía parlamentaria (de forma aislada o concertada), fueron unos pocos de los múltiples planteamientos que se habían propuesto a lo largo de los años para la consecución del socialismo ${ }^{42}$.

1. La primera gran vía de transformación de la sociedad era la que representaba la construcción de grandes sindicatos y partidos obreros que luchasen por la mejora de los salarios y de las condiciones de vida de la clase trabajadora, dentro del modo de producción capitalista. Estos partidos y organizaciones sindicales deberían pretender un avance lento, paulatino, suave, que situase el conflicto social dentro de los límites del constitucionalismo. El resultado de este camino, que supone la aceptación del sistema

41 García MaRzÁ, V. D.: Ética ..., op. cit., p. 190.

42 Geoghegan, Vincent: Socialismo, en AA.VV., Ideologias politicas, Tecnos, Madrid, 1993, p.122. 
legal vigente, es el abandono del desiderátum revolucionario, del cambio drástico de la sociedad y de su estructura productiva. Este primer modelo de socialismo democrático daría lugar a las formas de democracia participativa que Adela Cortina define como modelo de democratización de los subsistemas sociales. Este modelo democratizador tuvo su máximo exponenente en la configuración del concepto de democracia social. Con la aparición en las economías de mercado de lo que se vino en denominar Estado Social aparecería un nuevo modelo de democracia, la denominada democracia social. Las bases de los planteamientos de democracia social radican en la separación hegeliana entre sociedad civil y Estado ${ }^{43}$. Podemos afirmar que, partiendo de supuestos hegelianos $y$ de la neta distinción (que no separación) entre el Estado y la sociedad civil, se vino planteando la visión del Estado como ente que tiende al desarrollo superior y libre de la personalidad de los individuos. Frente al Estado se sitúa la sociedad (sustentada sobre los valores de la propiedad, es decir, sobre la dominación de las cosas que se transforma en dominación sobre las personas $y$, con ello, estratificada en clases) que tiende a la servidumbre y dependencia física y moral de la personalidad ${ }^{44}$. Por todo ello, la corrección por el Estado de los efectos disfuncionales de la sociedad industrial competitiva no es sólo una exigencia ética, sino también una necesidad histórica, pues, se habrá de optar necesariamente entre la revolución o la reforma sociales. De este modo se conformará la democracia social, que se basará, desde el punto de vista constitucional, por el sufragio universal $y$, desde el punto de vista administrativo, por su orientación hacia la neutralización de las desigualdades sociales. Ferrando Badia ${ }^{45}$, siguiendo la misma línea expositiva, afirmaría que en el marco de la democracia liberal en transformación, los ciudadanos, y especialmente los proletarios, quieren, con el ejercicio de sus derechos políticos, lograr que el Estado promueva reformas de las estructuras sociales y políticas para la consecución de una verdadera democracia social. De esta manera, definirá la democracia social como aquélla que tiende a que se desarrollen las libertades del

43 Véase a título de ejemplo: HEGEL, G. W.F.: Filosofía del Derecho, Claridad, Argentina, 1987, p. 208.HI

44 Garcia Pelayo, M.: Las Transformaciones del Estado Contemporáneo, Alianza, Madrid, 1977, pp. 17 y ss.

45 FerRando Badía, J. : "De la democracia política a la democracia social y económica", en Revista de Estudios Políticos, n. ${ }^{\circ} 168,1969$, p. 99. 
hombre situado en un contorno social determinado. Sólo de este modo evitaría la democracia liberal perecer en manos del marxismo. Siguiendo estas mismas tesis de democracia social participativa, debemos destacar la obra de Claus Offe ${ }^{46}$. Este autor formulará un nuevo concepto transformador del término democracia económica vinculado a tesis participativas ${ }^{47}$. Desde su punto de vista, los nuevos planteamientos de democracia económica irán ligados a la crisis de los partidos políticos tradicionales. Ante tal situación de crisis, se plantea como alternativa, no un proceso de sustitución y pérdida de importancia de la forma organizativa de partidos políticos, sino una estrategia de «autotrascendencia « del partido, moviéndose de la democracia política a la económica. Todos los modelos de democratización económica partirán de la idea de que podría encauzarse la tensión entre el principio democrático de igual participación de las masas y el principio económico de poder desigual y privado de adopción de decisiones, instituyendo, por medio del éxito electoral y la legislación desde el Parlamento, organismos democráticos a nivel de empresas, sectores de la industria, ciudades, etc. El problema que nos encontramos será el siguiente, ¿cómo se puede producir la transformación expuesta? A finales de los años 70, Ralph Miliband ${ }^{48}$ ya apuntaba una de las grandes críticas al sistema democrático de la época; la existencia de una clase económica dominante que se puede traducir mediante su influencia social en un control sobre las decisiones políticas. Así, los cambios que se pretende producir en el sistema económico se deben enfrentar al control que tienen la clase dominante sobre esferas grandes y fundamentales de la vida económica: sobre la producción, la inversión y la exportación, que es infinitamente superior al poder que pueden ejercer los sindicatos de trabajadores, los cuales tienen reducida su actividad al mundo de la reivindicación salarial, a la negociación y al compro-

46 Offe, Claus: Partidos Políticos y nuevos movimientos sociales. Editorial Sistema, Madrid, 1992, pp. 62 y ss.

47 Las teoría de democracia económica defendida por Offe debe distinguinse radicalmente de la teoría económica, de la democracia de raíz liberal. Esta segunda postura, que tuvo su máximo exponente en la obra An Economic Theory of Democracy (DOWNS A., HARPER \& Row Publisher, New York, 1957), intenta ¡Q3 exponer una teoría de la democracia basada en el autointerés económico de los electores y los intercambios racionales entre las élites políticas. Evidentemente poco tiene que ver con los postulados vinculados a tesis de democracia participativa defendidas por Offe.

48 Miliband, Ralph: El Estado en la sociedad capitalista. Siglo XXI, Madrid, 1976, pp. 44 y ss. 
miso. Esta exposición de Miliband entroncaría con la crítica comunista a la democracia que expone Alf Ross ${ }^{49}$. Se sostiene desde el comunismo que, mientras el capitalismo como sistema económico siga existiendo, contará con tales ventajas a su favor que será imposible, en el marco de la democracia parlamentaria (pese a la libertad aparente de expresar cualquier opinión y de llevarla adelante), Ilegar a abolir el sistema económico y social vigente. La ineficacia de la democracia parlamentaria como instrumento para la consecución del socialismo, radica en que las estructuras y fuerzas económicas son más fuertes que todas las convenciones jurídicas. El capitalismo vivirá, por así decirlo, en un refugio subterráneo que no es accesible a la lucha política parlamentaria. La lucha parlamentaria en pro de la clase trabajadora sólo servirá para la realización de fintas y engañifas; la esclavitud económica de los trabajadores continuará hasta el día en que violentamente derroquen el Estado capitalista, sustituyendo la dictadura de la burguesía por la dictadura del proletariado. Estas formulaciones críticas con la democracia participativa vinculada a la socialdemocracia, esconden una de las grandes debates del socialismo: ¿Por qué en los regímenes de democracia representativa, con sufragio universal, los partidos socialistas de corte revolucionario no alcanzan el poder político de manera democrática, si el proletariado es numéricamente mayoría? ¿Por qué los trabajadores votan, desde la óptica marxista en contra de sus intereses? ¿Suponen estos mecanismos participativos un instrumento de desactivación del espíritu revolucionario de la población? Las respuestas han sido varias, desde las teorías de la alienación, hasta la defensa del poder económico como gran controlador invisible de la política, pasando por la tesis de Macpherson que culpa a los partidos políticos como domesticadores de la democracia ${ }^{50}$.

2. El segundo gran modelo de cambio político y social que había ensayado el socialismo es el revolucionario, que iría ligado al modelo de democracia participativa basado en la descentralización política que supondria la eliminación de la democracia representativa. La base de estos planteamientos estaba en el modelo soviético y fueron impulsados por la III Internacional. La vía revolucionaria suponía la lucha contra la democracia representativa y

49 Ross, A. : ¿Por qué democracia? Centro de Estudios Constitucionales, Madrid, 1989 , p. 75.

50 MacPherson, C. B. : La democracia liberal y su época. Alianza, Madrid, 1994, pp. 80 y ss. 
parlamentaria que es calificada de burguesa, siendo sustituida por una democracia directa sobre el pilar del consejo o soviet. Los resultados de esta segunda vía son bastante conocidos, la eliminación de las libertades individuales, la dictadura del partido único y la creación de un Estado policial y burocrático, que se convierten en el resultado más visible de este intento de superación de la democracia parlamentaria. Tras el fracaso soviético, queda claro el carácter imprescindible de la esfera parlamentaria y del pluralismo político. No obstante, se hace preciso proceder al estudio de las principales críticas vertidas por el marxismo contra la democracia política burguesa.

A la democracia representativa clásica, articulada mediante elecciones pluripartidistas periódicas celebradas mediante sufragio universal, se le habia opuesto históricamente la democracia económica, que fue frecuentemente defendida por sus partidarios como una democracia real frente a la democracia formal burguesa. En el substrato de la configuración de la democracia económica había la influencia del economicismo marxista; si la política y las instituciones jurídicas (y por tanto incluida en ellas la democracia) eran reflejo (superestructura) de las condiciones económicas (infraestructura), sólo "democratizando» las segundas conseguiríamos una auténtica democracia. Así, afirmará David Held que la esencia del pensamiento marxista, en lo referente al gobierno democrático, radica en que este tipo de gobierno es esencialmente inviable en una sociedad capitalista; la regulación democrática de la vida no podía realizarse bajo las limitaciones impuestas por las relaciones capitalistas de producción. Creia Marx necesario transformar las bases mismas de la sociedad para crear la posibilidad de una política democrática ${ }^{51}$. Del mismo modo, afirmará Bobbio ${ }^{52}$ que la teoría marxengelsiana el sufragio universal, que para el liberalismo había sido el punto de llegada del proceso de democratización del Estado, supondrá únicamente el punto de partida. A partir del sufragio universal se deberá producir un proceso democratizador de dos grandes modos: primero a través de la critica a la democracia representativa y a una apuesta por la democracia directa; $y$ en segundo lugar, y aquí considero este punto extremadamente importante, a través de la demanda de que la participación popular, y por lo tanto el control del poder desde lo bajo, se extienda de los órganos de decisión política a los de decisión económica, de algunos centros del aparato estatal a la empresa, de la sociedad política a la socie-

51 HeLD, D.: Modelos de democracia. Alianza Ensayo, Madrid, 2001, p. 152.

52 Bоввı, N.: Diccionario de Política I, México, 1994, p. 447. 
dad civil. Será precisamente en este ámbito en el que se formularán, desde perspectivas marxistas, los conceptos democracia económica e industrial, con la esperanza que los nuevos órganos de control (los denominados Consejos Obreros) sirvan de instrumento para el paso del autogobierno a la autogestión. De este modo se cumpliría lo que Adela Cortina define como "descentralización política «, siendo las unidades de base (en el modelo ruso los soviets) el punto de partida de las decisiones políticas, siempre coordinadas por una instancia central.

\section{CONCLUSIONES}

Ante la configuración de una teoría de la democracia sobre presupuestos participativos, nos encontramos con una cuestión ética de gran calado. El punto de inflexión que supuso la crisis económica vinculada al aumento del precio del petróleo, a mediados de los años setenta, provocó una nueva reacción de los postulados neoliberales. Con la crisis económica y social de la década de los setenta y los primeros años de los 80 se produce un renacer del liberalismo económico y también político. Sobre la premisa de more market, less State, se iniciaba un duro ataque al Estado de bienestar configurado durante la postguerra europea. A las victorias de Margaret Thatcher en el Reino Unido (marzo de 1979), y de Ronald Reagan en los Estados Unidos (noviembre de 1980) se les unió una ofensiva ideológica liberal encabezada en su aspecto filosófico por Robert Nozick, en el económico por Milton Friedman (y en general por toda la Escuela de Chicago), en el político por Hayeck, y en el jurídico por Hart ${ }^{53}$. El lema común de este nuevo liberalismo, en su vertiente libertaria, es eliminar aquellos controles políticos al mercado que suponen, desde su punto de vista, un freno al crecimiento económico. Bajo el calificativo de "crisis del Estado del Bienestar", se esconde un rebrote del individualismo, la responsabilidad propia y el espíritu del riesgo; en suma una fuerte reacción en contra del Estado benefactor o asistencial, aunque también de la regulación pública y de la expansión financiera del Estado. Todo ello puso de manifiesto la incompatibilidad entre el liberalismo de mercado $y$ la soberanía de la democracia política de corte social, como elementos básicamente incompatibles. Los principios de la democracia social, y con ellos los del Estado de bienestar, fueron objeto de duras críticas. Desde el

53 Rubio Carracedo, J.: Paradigmas de la Política: Del Estado justo al Estado legítimo (Platón, Marx, Raw/s, Nozick), Anthropos, Barcelona, 1990, p. 245. 
punto de vista ético, los libertarios y liberales de mercado lanzaron su ofensiva ideológica diciendo que la justicia social es un espejismo; que los derechos sociales son una versión moderna del desatino sobre zancos; la imposición obligatoria, una forma de hurto o, todavía peor, un tipo de trabajo forzoso ${ }^{54}$. La crítica de la nueva derecha al Estado de bienestar apunta un calado muy hondo; se trata de una crítica a la democracia social en general $y$ a la teoría de la ciudadanía en particular ${ }^{55}$. Ambas son acusadas de haber comprendido mal la naturaleza de la libertad y el conjunto de derechos individuales para protegerla. Los derechos sociales se han creado, aunque moralmente no pueden existir ${ }^{56}$. Domina la idea que los derechos colectivos son una categoría injustificada, poco o nada consistente teóricamente, innecesaria, políticamente incorrecta e incluso peligrosa ${ }^{57}$. Estos derechos colectivos de corte social aparecieron, desde una perspectiva histórica, como resultado de la revolución proletaria del siglo XIX, y se denominaron por ello "derechos de segunda generación", pues fueron derechos que nacieron en el intento de completar y superar los logros de los derechos conquistados por las revoluciones burguesas de finales del XVIII58. Fueron precisamente estos derechos el máximo exponente del crecimiento de mecanismos de democracia social en los Estados europeos occidentales. El ataque a la existencia de derechos de naturaleza colectiva ${ }^{59}$, y en especial de los derechos sociales, económicos y

54 HaRRIS, D.: La Justificación del Estado de Bienestar, Instituto de Estudios Fiscales, Madrid, 1990, p. 53. 18

55 HaRRIS, D.: La Justificación..., op. cit., p. 63.

56 Es un tema recurrente por el liberalismo el ataque a la existencia de derechos colectivos. Debe tenerse presente, a título de ejemplo, que incluso un liberal moderado como Dworkin construirá su entramado de filosofía jurídica sobre los derechos individuales que son considerados como triunfos frente a la mayoría. No obstante, se debe fijar una distinción radical entre el liberalismo igualitario (defendido a título de ejemplo por Rawls y Dworkin) del liberalismo reaccionario de Nozick o Buchanan; mientras los primeros admiten la posibilidad de derechos positivos o de prestación (en los que estarían incluidos buena parte de los derechos sociales) los segundos reniegan de ellos, admitiendo únicamente la existencia de derechos negativos o de abstención. No obstante, es común a ambos el recelo a la existencia de entes colectivos definidos y con derechos propios.

57 López CAlera, N. M.: ¿Hay derechos colectivos?, Ariel, Barcelona, 2000, p. 13.

58 DE CASTRO CID, B. : «Retos de la configuración sistemática de los derechos económicos, sociales y culturales", en Anuario de Filosofía del Derecho, Tomo XV, 1998.

59 Al margen de las filias o fobias con respecto a los derechos colectivos, es un tema sumamente discutido la definición y separación conceptual entre derechos individuales y sociales o colectivos. Benito de Castro, en el artículo citado en la nota anterior, afirmará que los derechos deberán ser caracterizados de individuales siempre que sean reconocidos en atención al sujeto titular en cuanto persona individual y como sociales siempre que sean atribuidos al grupo como colectividad (de modo que los participes individuales de ese grupo son beneficiarios sólo en su calidad de partícipes del conjunto). 
culturales, será por tanto un tema recurrente por el nuevo liberalismo, al suponer a su vez un ataque al Estado de bienestar y a la democracia social. La negación de derechos de naturaleza social y colectiva supone negar implicitamente las bases de la democracia participativa ${ }^{60}$. Todo ello provocará que estemos viviendo un proceso de crecimiento autocrático de las macrodecisiones económicas, vinculado a las posturas anticolectivistas de un liberalismo libertario que roza con el anarquismo reaccionario.

Partiendo de esta base, la pregunta básica que debemos formulamos a la hora de perfilar una moderna teoría de la democracia es la siguiente ¿Es suficiente y satisfactoria para una correcta configuración de la democracia la existencia de un sistema parlamentario con representantes electos en elecciones periódicas en las que se presenten una pluralidad de ofertas partidistas? Creo que no. De la misma manera que es incalificable de democrático, en el día de hoy, un régimen político que no respete los derechos humanos, la separación de poderes o la pluralidad informativa; debemos avanzar hacia una configuración amplia de la democracia, abarcando ámbitos como el económico o el laboral, presididos hoy por decisiones autocráticas. Como bien afirma el profesor López Calera61, una sociedad civil, sobre todo en los ámbitos de lo económico y lo laboral, dejada al libre encuentro de los individuos y sometida a un genérico control de un Estado mínimo-policía reproduce y amplia las injusticias y desigualdades. Partiendo de estos presupuestos, los ataques a lo que supuso el Estado Social y a los mecanismos de democracia participativa son ataques al mismo núcleo de la democracia. De la misma manera que se debe reconocer que no es factible un sistema político que se autocalifique de democrático sin la existencia de un Parlamento elegido en elecciones periódicas, no es posible una auténtica democracia si el ámbito del mercado, y lo que vienen en denominarse desde posturas liberales como sociedad civil, está caracterizado por grandes decisiones al margen del control democrático. El proceso democratizador ha sido paulatino y sin pausas; la extensión del sufragio hasta alcanzar el universal masculino, la incorporación de la mujer al derecho al voto (con la gran lucha del movimiento sufragista), y la progresiva reducción de la edad electoral, son claros ejemplos de la extensión de la democracia en el ámbito político. Los mecanismos de democracia industrial fueron un gran intento, con éxitos desiguales, de democracia social producido en la posguerra europea, que

60 Derechos como el de sindicación, negociación colectiva o huelga son de marcado carácter colectivo. La negación genérica, desde un punto de vista ético, de los derechos colectivos supone un ataque indirecto a los mecanismos de democracia participativa.

61 López Calera, Nicolás M.: Yo, El Estado, Trotta, Madrid, 1992, p. 12. 
fue íntimamente ligado al nacimiento del Estado de bienestar. Este proceso no debe detenerse y no deben permitirse los retrocesos. Sólo de este modo conseguiremos alcanzar una nueva formulación de la democracia participativa y una consolidación definitiva de la democracia política representativa. 